\title{
Visual attention deficits in developmental dyslexia cannot be ascribed solely to poor reading experience
}

\section{Muriel Lobier and Sylviane Valdois}

In her recent Opinion article (Sensory theories of developmental dyslexia: three challenges for research. Nature Rev. Neurosci. 16, 43-54 (2015)) ${ }^{1}$, Goswami argues that sensory deficits, including the visual attention (VA) span deficit, are a consequence rather than a cause of developmental dyslexia. She further asserts that the poor performance of people with dyslexia on multiple-letter verbal-report tasks indicates poor individual-letter processing and impaired access to phonology rather than a reduced visual processing capacity as proposed by the VA span hypothesis ${ }^{2}$. Here, we claim that that this interpretation is not consistent with the current data.

First, if poor VA span performance was a consequence of poor reading, then all children with reading impairments would be expected to have a VA span deficit, which is not the case $\mathrm{e}^{2-5}$. By contrast, the VA span deficit in children with dyslexia is evident even when they are compared with younger children at the same reading level ${ }^{6,7}$.

Second, results from a recent training case study provide further evidence of causality. In this study, VA span training resulted not only in better reading performance but also in reactivation of the cortical areas that are associated with the VA $\operatorname{span}^{8}$. Furthermore, the VA span disorder has been reported in different languages (French and English ${ }^{2}$, and Portuguese ${ }^{3}$, with modulated effects in bilingual individuals that vary according to the language $e^{8,9}$. Although longitudinal studies are required to further demonstrate causality, the available data strongly argue against a lack of reading experience as an underlying factor for poor a VA span performance.

Last, Goswami argues for a linguistic interpretation of the VA span deficit based on evidence that the disorder does not extend to coloured dots or unfamiliar symbols. However, poor visual-to-phonology mapping should have predicted poor performance on the coloured-dots reporting task, which requires fast phonological recoding - this is not supported by the data ${ }^{10}$. Furthermore, if this argument is correct, VA span performance should strongly correlate with rapid automatized naming performance, which specifically measures visual-to-phonology mapping. In addition, both VA span performance and rapid automatized naming performance should similarly correlate with reading performance; however, these two predictions are not supported by the available data ${ }^{11}$. Finally, the absence of a deficit for a difficult-symbol VA span task in individuals with dyslexia ${ }^{12}$ could result from poor nearfloor performance of children both with and without dyslexia. Results that were obtained using an easier categorization task strongly indicate a similar deficit for unfamiliar, non-verbal characters in VA span-impaired children with dyslexia ${ }^{13}$. Participants were briefly presented with strings composed of either alphanumeric and familiar characters or non-alphanumeric unfamiliar characters. The participants had to identify the visual category of each character, but no verbal report was required. At the behavioural level, children with dyslexia were as severely impaired for non-alphanumeric strings as they were for alphanumeric strings. At the neural level, adults with dyslexia exhibited reduced superior parietal BOLD (bloodoxygen-level-dependent) activity regardless of the character type and familiarity ${ }^{14}$.

Despite the relevance of Goswami's general claim, her arguments do not apply to the VA span hypothesis. The overall findings argue against the proposition that the VA span deficit is a consequence of reduced reading experience or poor letter-specific processing. By contrast, a reduction in the amount of visual information that can be processed in parallel could explain the inability of children with dyslexia to acquire automatic word recognition, which is a characteristic of fluent reading ${ }^{15,16}$.

Muriel Lobier is at the Neuroscience Center, University of Helsinki, P.O. BOX 56, Fl-00014, Finland.

Sylviane Valdois is at the Laboratoire de Psychologie et NeuroCognition (LPNC), Centre National de la Recherche Scientifique (CNRS), UMR5105, F-38000 Grenoble, France; and the Université Grenoble Alpes, LPNC, F-38000 Grenoble, France.

Correspondence to M.L. e-mail:muriel.lobier@gmail.com doi: 10.1038/nrn3836-c 1 Published online 20 March 2015

1. Goswami, U. Sensory theories of developmental dyslexia: three challenges for research. Nature Rev. Neurosci. 16, 43-54 (2015).

2. Bosse, M.-L., Tainturier, M. J. \& Valdois, S Developmental dyslexia: the visual attention span deficit hypothesis. Cognition 104, 198-230 (2007)

3. Germano, G. D., Reilhac, C., Capellini, S. A. \& Valdois, $\mathrm{S}$. The phonological and visual basis of developmental dyslexia in Brazilian Portuguese reading children. Front. Psychol. 5, 1169 (2014).

4. Valdois, S. et al. Phonological and visual processing deficits can dissociate in developmental dyslexia: evidence from two case studies. Read. Writ. 16 541-572 (2003).

5. Peyrin, C. et al. Neural dissociation of phonological and visual attention span disorders in developmental dyslexia: FMRI evidence from two case reports. Brain Lang. 120, 381-394 (2012).

6. Zoubrinetzky, R., Bielle, F. \& Valdois, S. New insights on developmental dyslexia subtypes: heterogeneity of mixed reading profiles. PIOS ONE 9, e99337 (2014).

7. Bosse, M. L. \& Valdois, S. Patterns of developmental dyslexia according to a multi-trace memory model of reading. Curr. Psychol. Lett. 1, 10 (2003).

8. Valdois, S. et al. Dyslexia in a French-Spanish bilingual girl: behavioural and neural modulations following a specific visual-attention span intervention program. Cortex 53, 120-145 (2014).

9. Lallier, M., Valdois, S., Lassus-Sangosse, D., Prado, C. $\Sigma$ Kandel, S. Impact of orthographic transparency on typical and atypical reading development: evidence in French-Spanish bilingual children. Res. Dev. Disabil. 35, 1177-1190 (2014).

10. Valdois, S., Lassus-Sangosse, D. \& Lobier, M. Impaired letter-string processing in developmental dyslexia: what visual-to-phonology code mapping disorder? Dyslexia 18, 77-93 (2012).

11. van den Boer, M., de Jong, P. \& Haentjens-van Meeteren, M. Modeling the length effect: specifying the relation with visual and phonological correlates of reading. Sci. Stud. Read. 17, 243-256 (2013).

12. Ziegler, J. C. et al. Rapid processing of letters, digits and symbols: what purely visual-attentional deficit in developmental dyslexia? Dev. Sci. 13, F8-F14 (2010)

13. Lobier, M., Zoubrinetzky, R. \& Valdois, S. The visual attention span deficit in dyslexia is visual and not verbal. Cortex 48, 768-773 (2012).

14. Lobier, M., Peyrin, C., Pichat, C., Le Bas, J. F. \& Valdois, S. Visual processing of multiple elements in the dyslexic brain: evidence for a superior parietal dysfunction. Front. Hum. Neurosci. 8, 479 (2014).

15. Ans, B., Carbonnel, S. \& Valdois, S. A connectionist multiple-trace memory model for polysyllabic word reading. Psychol Rev 105, 678-723 (1998).

16. Lobier, M., Dubois, M. \& Valdois, S. The role of visual processing speed in reading speed development. PLOS ONE, 8 e58097 (2013).

Competing interests statement

The authors declare competing interests; see Web version for details. 